\title{
Criptógamos do Parque Estadual das Fontes do Ipiranga, São Paulo, SP, Brasil. Fungos, 10: Ganodermataceae
}

\author{
Adriana de Mello Gugliotta ${ }^{1,2}$, Grazielle Dias Poscolere ${ }^{1}$ e Thiago Vinicius Silva Campacci ${ }^{1}$
}

Recebido: 29.08.2011; aceito: 29.12.2011

\begin{abstract}
Cryptogams of the "Parque Estadual das Fontes do Ipiranga", São Paulo, São Paulo State, Brazil. Fungi, 10: Ganodermataceae). A survey of Ganodermataceae species from "Parque Estadual das Fontes do Ipiranga", Municipality of São Paulo, São Paulo State, Brazil was carried out. Twelve species were identified: Amauroderma aurantiacum (Torrend) Gibertoni \& Bernicchia, A. calcigenum (Berk.) Torrend, A. oblongisporum J.S. Furtado, A. pseudoboletus (Speg.) J.S. Furtado, A. rude (Berk.) Torrend, A. schomburgkii (Mont. \& Berk.) Torrend, A. sprucei (Pat.) Torrend, Ganoderma australe (Fr.) Pat., G. multiplicatum (Mont.) Pat., G. orbiforme (Fr.) Ryvarden, G. perzonatum Murrill, G. zonatum Murrill. Ganoderma perzonatum and G. zonatum are new records for São Paulo State. Comments of the taxa studied and descriptions and figures of microscopical features of new recorded species are provided herewith. An identification key to the species is also provided. Key words: Atlantic Forest, Basidiomycota, biodiversity, taxonomy
\end{abstract}

RESUMO - (Criptógamos do Parque Estadual das Fontes do Ipiranga, São Paulo, SP, Brasil. Fungos, 10: Ganodermataceae). Foi realizado levantamento das espécies de Ganodermataceae que ocorrem no Parque Estadual das Fontes do Ipiranga (PEFI), Município de São Paulo, Estado de São Paulo, Brasil. Foram identificadas doze espécies: Amauroderma aurantiacum (Torrend) Gibertoni \& Bernicchia, A. calcigenum (Berk.) Torrend, A. oblongisporum J.S. Furtado, A. pseudoboletus (Speg.) J.S. Furtado, A. rude (Berk.) Torrend, A. schomburgkii (Mont. \& Berk.) Torrend, A. sprucei (Pat.) Torrend, Ganoderma australe (Fr.) Pat., G. multiplicatum (Mont.) Pat., G. orbiforme (Fr.) Ryvarden, G. perzonatum Murrill, G. zonatum Murrill. Ganoderma perzonatum e G. zonatum constituem novas citações para o Estado de São Paulo. São apresentados comentários para cada táxon estudado, bem como descrições e figuras de estruturas microscópicas das espécies que constituem novos registros. Chave de identificação das espécies ocorrentes no Parque também é apresentada.

Palavras-chave: Basidiomycota, biodiversidade, Mata Atlântica, taxonomia

\section{Introdução}

Ganodermataceae Donk (Polyporales) é bem delimitada devido às características dos basidiósporos que não são encontrados nas demais famílias de fungos poliporóides: globosos a elipsóides, com paredes duplas, sendo a interna ornamentada, espessa e geralmente colorida, e a parede externa lisa, fina e hialina (Gilbertson \& Ryvarden 1986, Ryvarden 2004). Características como dimensões e ornamentações dos basidiósporos, bem como a estrutura da cobertura pilear, são imprescindíveis para a identificação das espécies de Ganodermataceae (Furtado 1981, Ryvarden 2004).

A família apresenta ampla distribuição abrangendo cerca de 117 espécies distribuídas em quatro gêneros: Amauroderma Murrill, Ganoderma P. Karst.,
Haddowia Steyaert e Humphreya Steyaert (Kirk et al. 2008).

Com exceção de Haddowia que foi registrada apenas para o Estado do Pará (Gomes-Silva et al. 2011), os demais gêneros estão bem representados nos trópicos, ocorrendo em diversos ecossistemas brasileiros (Torrend 1920, Furtado 1981, Gibertoni \& Cavalcanti 2003, Ryvarden 2004, Loguercio-Leite et al. 2005, Góes Neto \& Baseia 2006, Meijer 2006, Reck \& Silveira 2008, Silveira et al.2008, Campacci \& Gugliotta 2009, Gomes-Silva \& Gibertoni 2009, Gugliotta et al. 2010a,b, Westphalen et al. 2010, Gomes-Silva et al. 2011).

Os únicos estudos sobre a ocorrência da família no Parque Estadual das Fontes do Ipiranga (PEFI) foram realizados por Bononi et al. 1981, que publicaram uma listagem das espécies de fungos macroscópicos

1. Instituto de Botânica, Caixa Postal 68041, 04045-972 São Paulo, SP, Brasil

2. Autor para correspondência: agugliottaibot@yahoo.com.br 
depositados no Herbário do Instituto de Botânica (SP), e por Jesus (1993), que apresentou, uma comparação dos basidiomicetos lignocelulolíticos de uma área de floresta nativa e de uma floresta de Pinus elliottii, presentes no interior do PEFI, ambos sem qualquer descrição ou ilustração das espécies.

Furtado (1981) realizou a revisão do gênero Amauroderma, tendo citado para o Parque a ocorrência de A. aurantiacum (Torrend) Gibertoni \& Bernicchia (como A. macrosporum J.S. Furtado), A. calcigenum (Berk.) Torrend, A. macrosporum J.S. Furtado, A. pseudoboletus (Speg.) J.S. Furtado, A. rude (Berk.) Torrend e A. sprucei (Pat.) Torrend, sendo o material citado por ele também relacionado por Bononi et al. (1981). Além dessas, foram relacionadas para o PEFI as seguintes espécies de Ganoderma: G. applanatum (Pers.) Pat. (Bononi et al. 1981), G. australe (Fr.) Pat. e G. lucidum (Curtis) P. Karst. (Jesus 1993).

Este trabalho faz parte de um amplo projeto de levantamento de fungos basidiomicetos do Parque Estadual das Fontes do Ipiranga e apresenta os resultados para a família Ganodermataceae.

\section{Material e métodos}

O Parque Estadual das Fontes do Ipiranga (PEFI) situa-se no município de São Paulo (233'00"S2340'18'S e 46036'48"-46 38'08'W), ocupando uma área de 549,31 ha com altitude média de $798 \mathrm{~m}$. A vegetação é caracterizada como floresta ombrófila densa e representa um dos mais significativos remanescentes de mata inserido em área urbana do município. Aspectos climáticos, do meio físico e da vegetação podem ser encontrados em Bicudo et al. (2002).

Foram realizadas coletas bimensais no período de abril de 2000 a março de 2001, e de agosto de 2006 a abril de 2007. O material foi coletado segundo recomendações técnicas de Fidalgo \& Bononi (1984) e encontra-se depositado no Herbário do Instituto de Botânica (SP). Também foram revisadas as exsicatas depositadas no Herbário SP provenientes de coletas anteriores, incluindo o material citado por Bononi et al. (1981).
A identificação foi realizada pela análise dos caracteres macro e microscópicos do basidioma, e as microestruturas analisadas segundo as recomendações de Fidalgo (1968) e Teixeira $(1962,1995) \mathrm{em}$ microscópio LEICA DM-1000 com aumento de 800 a 1.000 vezes, sendo realizadas em média, 20 medições de cada tipo de estrutura. As reações amiloide e dextrinoide foram testadas com reagente de Melzer (Gilbertson \& Ryvarden 1986, Teixeira 1995).

Para identificação foi utilizada bibliografia pertinente, como Furtado (1981), Ryvarden (1991, 2004) e Loguercio-Leite et al. (2005), e comparação com outros espécimes depositados no Herbário Maria Eneyda P.K. Fidalgo (SP).

A classificação segundo Kirk et al. (2008), pode ser consultada nas bases de dados CABI (2011) e CBS-KNAW (2011).

São apresentados chave de identificação para as espécies presentes no PEFI, comentários para cada táxon estudado, bem como descrições e figuras de estruturas microscópicas das espécies que constituem novos registros para o Estado.

\section{Resultados e Discussão}

A família está representada no Parque por doze espécies: Amauroderma aurantiacum (Torrend) Gibertoni \& Bernicchia, A. calcigenum (Berk.) Torrend, A. oblongisporum J.S. Furtado, A. pseudoboletus (Speg.) J.S. Furtado, A. rude (Berk.) Torrend, A. schomburgkii (Mont. \& Berk.) Torrend, A. sprucei (Pat.) Torrend, Ganoderma australe (Fr.) Pat., G. multiplicatum (Mont.) Pat., G. orbiforme (Fr.) Ryvarden, G. perzonatum Murrill e G. zonatum Murrill. Ganoderma perzonatum e G. zonatum constituem novas citações para o Estado de São Paulo.

A ocorrência de Ganoderma lucidum citada por Jesus (1993) não foi confirmada, pois somente umúnico espécime identificado por aquele autor foi localizado no Herbário SP (SP 211911), e re-identificado como G. orbiforme. Os espécimes relacionados por Bononi et al. (1981) como G. applanatum foram re-identificados como G. australe.

Chave de identificação para as espécies de Ganodermataceae que ocorrem no PEFI

1. Basidioma estipitado, basidiósporos globosos a subglobosos, ocasionalmente elipsoides, não truncados

2. Poros $0,5-1$ por $\mathrm{mm}$

3. Basidiósporos globosos, 13,2-14,8 $\mu \mathrm{m}$ diâm. Amauroderma aurantiacum

3. Basidiósporos oblongos a elipsoides, $12,5-15 \times(8,75-) 11,2-12 \mu \mathrm{m}$ Amauroderma calcigenum

2. Poros 3-7 por mm

4. Basidiósporos oblongo-elipsoides, com projeções endospóricas pouco conspícuas 
4. Basidiósporos globosos a subglobosos, com projeções endospóricas conspícuas

5. Poros 3-4 por mm

6. Superfície pilear do tipo córtex, basidiósporos grandes $12,5-13,75(-15) \times 11,25-12,5(-13,75) \mu \mathrm{m}$. Amauroderma pseudoboletus

6. Superfície pilear do tipo derme, basidiósporos menores (8-)8,8-10,4(-11,2) $\mu \mathrm{m}$ diâm.

Amauroderma rude

5. Poros 5-7 por $\mathrm{mm}$

7. Contexto castanho-dourado a castanho-escuro, superfície pilear do tipo córtex Amauroderma. schomburgkii

7. Contexto branco a creme, escurecendo levemente com a maturidade ou desidratação, superfície pilear do tipo derme Amauroderma sprucei

1. Basidioma pileado séssil, ocasionalmente estipitado, basidiósporos amplamente elipsoides com ápice truncado

8. Superfície pilear opaca, castanha a castanho-escura Ganoderma australe

8. Superfície pilear lacada, avermelhada, escurecendo a quase preta, próximo à base

9. Células da cutícula com elementos fracamente amiloides, lisas, claviformes, com pequenas granulações no ápice Ganoderma perzonatum

9. Células da cutícula amiloides, sinuosas, com protuberâncias ou lóbulos

10. Células da cutícula pouco sinuosas, regulares, raras protuberâncias ou lóbulos

Ganoderma multiplicatum

10. Células da cutícula bastante sinuosas, irregulares, com protuberâncias ou lóbulos, algumas com ápice expandido ou dividido em duas partes

11. Basidiósporos elipsoides, 8,8-10,4 ×6,4-7,2 $\mu \mathrm{m}$ Ganoderma orbiforme

11. Basidiósporos oblongo-elipsoides, 10,4-11,2 × 5,6-6 $\mu \mathrm{m}$ Ganoderma zonatum

Amauroderma aurantiacum (Torrend) Gibertoni \& Bernicchia, Mycotaxon 104:322.2008 $\equiv$ Ganoderma aurantiacum Torrend, Iconogr. Mycol. 22: 1007.1932 = Amauroderma macrosporum J.S. Furtado, Revisão do gênero Amauroderma (Polyporaceae); Estudos baseados nas microestruturas do basidiocarpo: 203. 1968.

Descrição e ilustração: Furtado (1981) e Ryvarden (2004), ambos como Amauroderma macrosporum.

Material examinado: BRASIL. São PAULO: São Paulo, Parque Estadual das Fontes do Ipiranga, 6-II-1960, J.S. Furtado \& O. Fidalgo s.n. (SP47626); idem, 16-II-1960, M.E.P.K. Fidalgo \& J.S. Furtado s.n. (SP47598, holótipo de A. macrosporum); idem, 22-VI-1961, E.S. Beneke et al. s.n. (SP95112); idem, 31-X-1969, D.M. Dring s.n. (SP107205), idem, 16-III-1970, B. Skvortzov s.n. (SP107542); idem, 15-I-2007, T.V.S. Campacci \& F. Karstedt 11 (SP).

A espécie caracteriza-se pelo basidioma anual, centralmente estipitado, solitário; superfície abhimenial castanho-avermelhada, poros angulares, grandes, 1-2 mm diâm., superfície pilear do tipo córtex e basidiósporos globosos, amarelados, asperulados, com projeções endospóricas salientes, 13,2-14,8 $\mu$ m diâm.
Amauroderma calcigenum (Berk.) Torrend, Brotéria, sér. bot. 13: 129. $1920 \equiv$ Polyporus calcigenus Berk., J. Bot., London 2: 636. 1843.

Descrição e ilustração: Furtado (1981) e Ryvarden (2004).

Material examinado: BRASIL. São PAULO: São Paulo, Parque Estadual das Fontes do Ipiranga, 26-I-1960, M.E.P.K. Fidalgo \& J.S. Furtado s.n. (SP47596); idem, 5-V-1960, J.S. Furtado s.n. (SP47793); idem, I-1966, J.S. Furtado s.n. (SP92830); idem, 8-III-1967, J.S. Furtado s.n. (SP84006); idem, 15-IV-2003, M. Capelari s.n. (SP382039).

Amauroderma calcigenum caracteriza-se pelo basidioma anual, central a lateralmente estipitado, com superfície abhimenial castanho-clara a escura, brilhante, mas não lacada, poros circulares a angulares, 1-2 mm diâm., superfície pilear do tipo córtex e basidiósporos elipsoides a ligeiramente oblongos, palidamente amarelados, asperulados, $12,5-15 \times(8,75-) 11,2-12 \mu \mathrm{m}$.

Amauroderma oblongisporum J.S. Furtado, Revisão do gênero Amauroderma (Polyporaceae); Estudos baseados nas microestruturas do basidiocarpo: 208. 1968. 
Descrição e ilustração: Furtado (1981) e Campacci \& Gugliotta (2009).

Material examinado: BRASIL. São Paulo: São Paulo, Parque Estadual das Fontes do Ipiranga, 2-I-1970, B. Skvortzov s.n. (SP107239).

Amauroderma oblongisporum pode ser reconhecido pelo basidioma solitário a conato, com píleo circular formado pela fusão de vários píleos, superfície pilear castanho-clara a castanho-escura, zonada, poros circulares, $4-5 / \mathrm{mm}$, superfície pilear do tipo córtex e basidiósporos oblongo-elipsoides, palidamente amarelados com projeções endospóricas pouco conspícuas, $10-12,5 \times 6,25-7,5 \mu \mathrm{m}$.

Amauroderma pseudoboletus (Speg.) J.S. Furtado, Revisão do gênero Amauroderma (Polyporaceae); Estudosbaseadosnas microestruturas dobasidiocarpo: 230. 1968 EPolyporus pseudoboletus Speg., Anal.

Soc. cient. argent. 16: 279. 1883.

Descrição e ilustração: Furtado (1981) e Ryvarden (2004).

Material examinado: BRASIL. São PAULO: São Paulo, Parque Estadual das Fontes do Ipiranga, 11-II-1960, J.S. Furtado et al. s.n. (SP46647); idem, 13-II-1960, J.S. Furtado et al. s.n. (SP45547); idem, 27-III-1968, B. Skvortzov s.n. (SP103331).

A espécie pode ser reconhecida pela superfície pilear avermelhada a castanho-escura, poros circulares a angulares, $3-4 / \mathrm{mm}$, superfície pilear do tipo córtex, representada por hifas dispostas paralelamente em direção ao crescimento do píleo, com hifas bastante aglutinadas por exudado, basidiósporos globosos a subglobosos, amarelados, asperulados, com projeções endospóricas distintas, $12,5-13,75(-15) \times 11,25-12,5(-13,75)$ $\mu \mathrm{m}$. É morfologicamente semelhante a $A$. rude, que se diferencia pela estrutura pilear do tipo derme e basidiósporos menores (Furtado 1981, Ryvarden 2004).

Amauroderma rude (Berk.) Torrend, Brotéria, sér. bot. 18: 127. $1920 \equiv$ Fomes rudis Berk., Grevillea 13 (68): 117.1885

= Amauroderma intermedium (Bres. \& Pat.) Torrend, Brotéria, sér. bot. 18: 128. 1920.

Descrição e ilustração: Furtado (1981) e Ryvarden (2004).

Material examinado: BRASIL. São PAULo: São Paulo, Parque Estadual das Fontes do Ipiranga, 14-X-1960,
E.F. Campos s.n. (SP53449); idem, 22-X-1960, J.S. Furtado s.n. (SP54475); idem, 24-X-1960, J.S. Furtado s.n. (SP54473); idem, 25-X-1960, J.S. Furtado \& M.E.P.K. Fidalgo s.n. (SP53239; SP53469; SP53477; SP53481; SP53482; SP53486); idem, 22-XII-1960, J.S. Furtado \& D. Zago s.n. (SP54829); idem, 13-VI-1961, J.S. Furtado et al. s.n. (SP62045); idem, 7-XI-1961, J.S. Furtado \& J.R.P. Castro s.n. (SP61133; SP61134; SP62046; SP83943); idem, 9-IV-1962, J.S. Furtado s.n. (SP102714); idem, 26-IX-1967, B. Skvortzov s.n. (SP102026).

O basidioma castanho-escuro a cinza-enegrecido, poros circulares $3-4 / \mathrm{mm}$, superfície pilear do tipo derme e basidiósporos globosos, amarelados, asperulados, com projeções endospóricas conspícuas, (8-)8,8-10,4(-11,2) $\mu$ m diâm. são boas características para o reconhecimento da espécie.

Amauroderma schomburgkii (Mont. \& Berk.) Torrend, Brotéria, sér. bot. 18: 140. $1920 \equiv$ Fomes schomburgkii (Mont. \& Berk.) Sacc Grevillea 13 (68): 117. 1885.

Descrição e ilustração: Furtado (1981) e Ryvarden (2004).

Material examinado: BRASIL. São PAUlo: São Paulo, Parque Estadual das Fontes do Ipiranga, s.d., J.S. Furtado \& O. Fidalgo s.n. (SP47231); idem, s.d., J.S. Furtado s.n. (SP95969); idem, III-1944, M. Kuhlmann s.n. (SP12259); idem, 12-VII-1956, M. Kuhlmann s.n.(SP43142); idem, 14-V-1957, M.A. Pereira s.n. (SP39396); idem, 28-V-1959, A.C. Lucchesi s.n. (SP39094); idem, 1-I-1960, J.S. Furtado \& M.E.P.K. Fidalgo s.n. (SP47772); idem, 29-I-1960, J.S. Furtado et al. s.n. (SP47737; SP47771; SP51094); idem, 1-II-1960, J.S. Furtado et al. s.n. (SP47789; SP47791; SP47792); idem, 6-II-1960, J.S. Furtado \& O. Fidalgo s.n. (SP47749); idem, 11-II-1960, J.S. Furtado \& O. Fidalgo s.n. (SP47739; SP47758); idem, 15-II-1960, J.S. Furtado et al. s.n. (SP47206); idem, 16-II-1960, J.S. Furtado et al. s.n. (SP46649); idem, 24-II-1960, J.S. Furtado \& O. Fidalgo s.n. (SP47609; SP47610; SP47615; SP47618; SP47619; SP47620); idem, 4-III-1960, J.S. Furtado et al. s.n. (SP47625); idem, 8-III-1960, J. Amaral s.n. (SP47656); idem, 30-III-1960, J.S. Furtado et al. s.n. (SP47794; SP48089; SP48374; SP48375); idem, 5-V-1960, J.S. Furtado s.n. (SP48914; SP49536; SP51096); idem, 25-X-1960, M.E.P.K. Fidalgo \& J.S. Furtado s.n. (SP53438; SP54574); idem, 23-XII-1960, J.S. Furtado \& 
D. Zago s.n. (SP54603; SP54681; SP54806; SP54820; SP54821; SP54822; SP54852); idem, 15-II-1961, J.S. Furtado s.n. (SP54855; SP54860; SP54861; SP54863; SP54864; SP54867); idem, 7-III-1961, J.S. Furtado s.n. (SP102711; SP102712); idem, 23-III-1961, J.S. Furtado s.n. (SP56255; SP56256; SP56257; SP56258; SP56259); idem, 26-VI-1961, E.S. Beneke s.n. (SP62027); idem, 24-I-1962, J.S. Furtado s.n. (SP91538); idem, 24-I-1962, J.S. Furtado \& C.E.M. Bicudo s.n. (SP95744); idem, 7-III-1962, A.R.C. Salles \& J.S. Furtado s.n. (SP92827; SP95001); idem, 27-III-1962, J.S. Furtado s.n. (SP95966; SP95967; SP95968); idem, 29-III-1962, J.S. Furtado s.n. (SP95964); idem, 9-IV-1962, J.S. Furtado s.n. (SP102713); idem, I-1967, H. Requejo s.n. (SP98450); idem, 9-I-1968, J.S. Furtado s.n. (SP102090); idem, 15-I-1969, B. Skvortzov s.n. (SP103707); idem, 21-III-1969, B. Skvortzov s.n. (SP103778); idem, 1-IV-1969, B. Skvortzov s.n. (SP103853); idem, 27-VI-1969, B. Skvortzov s.n. (SP106733); idem, 2-VII-1969, B. Skvortzov s.n. (SP106757); idem, 26-XII-1969, B. Skvortzov s.n. (SP107272); idem, 21-I-1970, B. Skvortzov s.n. (SP107425); idem, 23-I-1970, B. Skvortzov s.n. (SP107462; SP107477); 2-II-1970, B. Skvortzov s.n. (SP107502); idem, 16-II-1970, B. Skvortzov s.n. (SP107469); idem, 18-III-1970, B. Skvortzov s.n. (SP107533); idem, 29-IV-1970, B. Skvortzov s.n. (SP107684); idem, 13-II-2007, T.V.S. Campacci \& M. Capelari 017 (SP).

A espécie caracteriza-se pelo basidioma castanho-enegrecido, poros circulares a angulares, 5-6/mm, superfície pilear do tipo córtex e basidiósporos globosos, hialinos, com projeções endospóricas pouco nítidas, 7-10 $\mu \mathrm{m}$ diâm.

Amauroderma sprucei (Pat.) Torrend, Brotéria, sér. bot. 18: 121. 1920 三 Ganoderma sprucei Pat., Bull. Soc. mycol. Fr. 10(2): 75. 1894.

Descrição e ilustração: Furtado (1981) e Ryvarden (2004).

Material examinado: BRASIL. São PAULO: São Paulo, Parque Estadual das Fontes do Ipiranga, 24-II-1960, O. Fidalgo \& J.S. Furtado s.n. (SP47616).

Amauroderma sprucei é morfologicamente semelhante a $A$. schomburgkii, do qual difere pela superfície pilear alaranjada a castanho-avermelhada, contexto homogêneo branco a creme, estrutura da superfície pilear do tipo derme, e basidiósporos globosos com projeções endospóricas bem nítidas, (6-)8-10 بm diâm.
Ganoderma australe (Fr.) Pat., Bull. Soc. mycol. Fr. 5: $65,1890 \equiv$ Polyporus australis Fr., Elench. fung. (Greifswald) 1: 108. 1828.

Figuras 1-2

Descrição: Ryvarden (2004).

Material examinado: BRASIL. São PAUlo: São Paulo, Parque Estadual das Fontes do Ipiranga, s.d., A.R. Salles \& Y.C. Furtado s.n. (SP95701); idem, 10-II-1943, A. Gehrt s.n. (SP38354); 2-VI-1956, M.A. Pereira s.n. (SP40060); idem, 18-VI-1956, C.A. dos Santos s.n. (SP38370); idem, 8-V-1957, M.A. Pereira s.n. (SP35476); idem, 14-V-1959, J.S. Furtado s.n. (SP35362); idem, 21-V-1959, J.S. Furtado s.n. (SP35344); idem, 18-IX-1959, R. Locatelli s.n. (SP47346); idem, 29-I-1960, J.S. Furtado et al. s.n. (SP46776); idem, 8-II-1960, J.S. Furtado et al. s.n. (SP48791); idem, 15-II-1960, J.S. Furtado et al. s.n. (SP47302); idem, 16-II-1960, J.S. Furtado et al. s.n. (SP46641); idem, 18-II-1960, J.S. Furtado et al. s.n. (SP46642); idem, VI-1960, E.F. Campos \& J.R.P. Castro s.n. (SP50042); idem, 25-X-1960, M.E.P.K. Fidalgo \& J.S. Furtado s.n. (SP53123; SP53464); idem, 22-XI-1960, E.F. Campos \& A.R. Salles s.n. (SP53518; SP53569); idem, 24-III-1961, A.R. Salles s.n. (SP60386); idem, 8-V-1961, A.R. Salles \& Daniel s.n. (SP95703); idem, 19-VII-1961, V.P. de Souza s.n. (SP60819); idem, 12-X-1961, A.R. Salles s.n. (SP95137); idem, 27-XI-1961, A.R. Salles \& D. Francisco s.n. (SP61457); idem, 17-IV-1962, A.R. Salles s.n. (SP94927); idem, 3-VII-1962, A.R. Salles \& J. Souza s.n. (SP95754); idem, 18-X-1962, L. Zimmermann \& A.R. Salles s.n. (SP95315); idem, X-1963, B. Skvortzov s.n. (SP95095); idem, 25-IV-1964, B. Skvortzov s.n. (SP95024); idem, 6-I-1966, M.C. Marino s.n. (SP83974); idem, 9-I-1967, V.P. de Souza s.n. (SP98019); idem, 4-IV-1967, V.P. de Souza s.n. (SP84014); idem, 22-VIII-1967, V.P. de Souza s.n. (SP98488; SP98489); idem, 9-IV-1974, L.C. de Abreu s.n. (SP124287); idem, 4-VI-1974, L.C. de Abreu s.n. (SP124381); idem, 18-VI-1974, L.C. de Abreu s.n. (SP124380); idem, 14-VIII-1976, B. Skvortzov s.n. (SP109164); idem, 3-VI-1977, A.I. Milanez s.n. (SP141574); idem, 11-IV-1979, R.A. Piccolo \& A.C. Grandi s.n. (SP156740); idem, 19-III-1980, M.S.F. Silvestre 232 (SP); idem, 16-I-1986, M.A. de Jesus s.n. (SP211927); idem, 24-II-1986, M.A. de Jesus s.n. (SP211910); idem, 4-I-1988, M. Capelari s.n. (SP94931); idem, 5-V-1993, A.M. Gugliotta s.n. (SP250769); idem, 24-XI-1995, A.M. Gugliotta et al. s.n. (SP251121); 
idem, 18-III-1998, L.K. Okino s.n. (SP382042); idem, 3-X-2003, A.M. Gugliotta et al. 1188 (SP); idem, 20-X-2006, T.V.S. Campacci et al. 06 (SP).

Ganoderma australe pode ser reconhecido pelo basidioma lenhoso, perene, com superfície pilear opaca, cutícula espessa e muito rígida e basidiósporos geralmente maiores que $8 \mu \mathrm{m}$ de compr. (Leonard 1998, Zhao 1989, Ryvarden 2004).

Os espécimes encontrados no Parque Estadual das Fontes do Ipiranga foram cuidadosamente analisados e observou-se que os mesmos apresentam grande variação nas dimensões dos basidiósporos; enquanto um grupo (SP53569; SP94927; SP94931; SP98488; SP141574; SP382042) apresenta basidiósporos de 6,4-8 × (4-)4,8-5,6 $\mu \mathrm{m}$ (figura 1), os demais espécimes possuem basidiósporos maiores, (8-) $8,8-10,4(-11,2) \times 5,6-7,2(-8) \mu \mathrm{m}$ (figura 2). Para a obtenção dessas medidas, foram realizadas 20 a 30 medições em todos os espécimes estudados.

Segundo Zhao (1989) e Leonard (1998), os espécimes com basidiósporos menores corresponderiam a Ganoderma applanatum (Pers.) Pat., enquanto que os demais, com basidiósporos maiores, a G. australe. Ryvarden (2004), no entanto, salienta que $G$. applanatum, além de apresentar certas diferenças morfológicas, como basidiósporos menores, cutícula mais fina e ausência de bandas negras no contexto, apresenta distinta distribuição geográfica estando restrito a zonas temperadas. No entanto, características como espessura da cutícula, presença de bandas negras no contexto e presença de contexto entre as camadas de tubos, normalmente utilizadas para auxiliar na separação entre estas espécies, são extremamente variáveis e nem sempre facilmente observadas, principalmente em espécimes mais jovens (Leonard 1998).

Estudos morfológicos e moleculares vêm demonstrando que o complexo Ganoderma applanatum-australe é composto por várias espécies crípticas, cujas características morfológicas são insuficientes para separá-las. Moncalvo \& Buchanan (2008) realizaram um estudo molecular obtendo sequências da região ITS de rDNA de 98 espécimes, os quais agruparam em oito clados distintos, fortemente relacionados à origem geográfica: um clado proveniente do Hemisfério Norte, dois clados do Hemisfério Sul, um clado com espécies da região do Hemisfério Sul e Ásia oriental, três clados Asiáticos e um clado Neotropical. Neste estudo apenas um espécime proveniente do Brasil foi analisado, o qual aparece incluído no clado Neotropical. De acordo com estes resultados, é possível que mais de uma espécie do complexo ocorra no Brasil.

No entanto, apesar de termos observado grande variação nas características morfológicas entre os espécimes do PEFI, principalmente em relação às dimensões dos basidiósporos, optamos por agrupá-los todos sob o nome Ganoderma australe, que tem sido considerado válido para as espécies neotropicais, até que futuros estudos moleculares, genéticos e morfológicos, incluindo mais espécimes brasileiros, possam esclarecer a real situação das espécies do complexo.

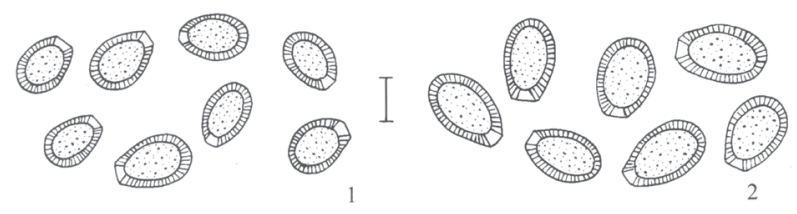

Figuras 1-2. Basidiósporos de Ganoderma australe. Barra de escala $=5 \mu \mathrm{m}$.

Figures 1-2. Basidiospores of Ganoderma australe. Bar Scale $=5 \mu \mathrm{m}$.

Ganoderma multiplicatum (Mont.) Pat., Bull. Soc. mycol. Fr. 5(2,3):74. 1889 $\equiv$ Polyporus multiplicatus Mont., Annls Sci. Nat., Bot., sér. 4, 1: 128. 1854. Figuras 3-4

Descrição: Ryvarden (2004).

Material examinado: BRASIL. São PaUlo: São Paulo, Parque Estadual das Fontes do Ipiranga, 29-I-2007, T.V.S. Campacci 12 (SP).

Ganoderma multiplicatum caracteriza-se pelo basidioma lacado, séssil, lenhoso, aplanado, dimidiado, contexto dúplex com uma faixa preta resinosa e poros angulares, 4-6/mm. Microscopicamente, a cutícula formada por hifas de parede espessa a sólida, amiloides, com terminações clavadas, sinuosas, com raras protuberâncias, e os basidiósporos subglobosos a largamente elipsóides, castanho-amarelados, 7,2-8(-9,6) × 5,6-7,2 $\mu \mathrm{m}$ completam o diagnóstico. É morfologicamente semelhante a $G$. orbiforme que, no entanto, apresenta basidiósporos maiores 8,8-10,4 × 6,4-7,2 $\mu \mathrm{m}$, e células da cutícula com protuberâncias ou lóbulos mais desenvolvidos.

Ganoderma orbiforme (Fr.) Ryvarden [como 'orbiformum'], Mycologia 92 (1): 187. $2000 \equiv$ Polyporus orbiformis Fr., Epicr. syst. mycol. (Upsaliae): 463. 1838 [1836-1838].

Figuras 5-6

Descrição: Ryvarden (2004). 
Material examinado: BRASIL. S̃̃o Paulo: São Paulo, Parque Estadual das Fontes do Ipiranga, 31-III-1986, M.A. Jesus s.n. (SP211911); idem, 20-II-2002, A.M. Gugliotta 1178 (SP); idem, 7-II-2007, T.V.S. Campacci et al. 14 (SP); idem, 13-II-2007, T.V.S. Campacci 15 (SP); idem, 13-II-2007, T.V.S. Campacci 016 (SP); idem, 13-II-2007, T.V.S. Campacci \& M. Capelari 18 (SP); idem, 8-II-2006, A.M. Gugliotta \& T.V.S. Campacci 1225 (SP); idem, 31-III-2008, A.M. Gugliotta 1259 (SP).

A espécie pode ser reconhecida pelo basidioma séssil, aplanado, dimidiado, lacado, poros angulares (3-)4-5 por mm, células da cutícula claviformes, sinuosas, com pequenas protuberâncias ou lóbulos, alguns expandidos ou divididos em duas partes no ápice, fortemente amiloides, e basidiósporos elipsóides, truncados, 8,8-10,4 × 6,4-7,2 $\mu \mathrm{m}$.

Ganoderma perzonatum Murrill, N. Amer. Flora 9 (2): 121. 1980.

Figuras 7-8

Basidioma séssil, lenhoso, aplanado; píleo dimidiado, agregado, até $12 \mathrm{~cm}$ larg. e $3 \mathrm{~cm}$ espesso. Superfície pilear lacada, vermelho-escura, escurecendo a quase preta próximo à base, zonada, pouco rugosa, dificilmente altera-se quando pressionada com a unha. Contexto castanho-claro, com faixas resinosas pretas, 0,6 cm espesso. Superfície himenial poroide, amarelada, poros angulares a circulares, 4-5 por $\mathrm{mm}$; tubos concolores ao contexto, $0,7 \mathrm{~cm}$ compr. Células da cutícula claviformes, sem protuberâncias, pouco sinuosas, levemente dilatadas no ápice, parede espessa a sólida, algumas com pequenas granulações no ápice, levemente amareladas a hialinas, levemente amiloides. Sistema hifálico dimítico; hifas generativas hialinas, parede fina, com ansas, de difícil observação em espécimes secos, 2,4-4 $\mu \mathrm{m}$ diâm.; hifas esqueléticas abundantes, amareladas a palidamente castanhas, parede espessa, arboriformes, 6,4-10,4 $\mu \mathrm{m}$ diâm. Basídios não observados. Basidiósporos elipsóides, truncados, amarelados, $(8-) 8,8-9,6(-10,4) \times(5,6-) 6,4-7,2 \mu \mathrm{m}$.

Material examinado: BRASIL. São Paulo: São Paulo, Parque Estadual das Fontes do Ipiranga, 8-V-1961, A.R.Salles s.n. (SP61988); idem, 7-III-1962, A.R.C. Salles \& Y.C. Furtado, s.n. (SP61968); idem, 4-IV-1967, V.P. de Souza s.n. (SP83952).

O basidioma séssil, lenhoso, aplanado, com superfície pilear lacada, contexto castanho-claro, com faixas resinosas pretas, células da cúticula claviformes, sem protuberâncias e com granulações no ápice, e os basidiósporos elipsóides caracterizam a espécie. É morfologicamente semelhante a Ganoderma resinaceum Boud. e G. vivianimercedianum Torres-Torres que também ocorrem no Brasil. No entanto $G$. vivianimercedianum apresenta células da cutícula levemente mais estreitas e basidiósporos maiores, $8,8-11,2(-12) \times 6,4-8 \mu \mathrm{m}$, enquanto G. resinaceum, além dos basidiósporos maiores $11,2-13,6 \times 6,5-7,4(-8,1) \mu \mathrm{m}$, difere pelo contexto homogêneo (Torres-Torres et al. 2008). Trata-se da primeira citação para o Estado de São Paulo.

Ganoderma zonatum Murrill, Bull. Torrey bot. Club 29: 606. 1902.

Figuras 9-10

Basidioma séssil, lenhoso, aplanado; píleo dimidiado, agregado, até $30 \mathrm{~cm}$ larg. e $6 \mathrm{~cm}$ espesso. Superfície pilear lacada, avermelhada, zonada, às vezes rugosa, quando em crescimento apresenta borda amarelo-avermelhada. Contexto dúplex, castanho-escuro próximo aos tubos, clareando próximo à superfície pilear, com uma faixa resinosa, até $2 \mathrm{~cm}$ espesso. Superfície himenial poroide branca a creme, poros circulares, (3-)4 por mm; tubos castanho-escuros, até $3 \mathrm{~cm}$ compr. Células da cutícula bastante irregulares, claviformes, sinuosas, com protuberâncias e algumas ramificações, parede espessa a sólida, fortemente amilóides. Sistema hifálico dimítico; hifas generativas hialinas, parede fina, com ansas, de difícil observação, 2,4-3,2 $\mu \mathrm{m}$ diâm.; hifas esqueléticas abundantes, parede espessa, castanho-amareladas, ramificadas, algumas possuem uma reação levemente dextrinoide, 3,2-6,4 $\mu \mathrm{m}$ diâm. Basídios não observados. Basidiósporos oblongo-elipsoides, truncados, amarelados, $10,4-11,2 \times 5,6-6 \mu \mathrm{m}$.

Material examinado: BRASIL. São PAULO: São Paulo, Parque Estadual das Fontes do Ipiranga, 22-II-2007, T.V.S. Campacci 20 (SP).

Ganoderma zonatum caracteriza-se pelo basidioma séssil, lenhoso, aplanado, com superfície pilear lacada, contexto dúplex, com uma faixa resinosa, células da cutícula bastante irregulares, claviformes, sinuosas, com protuberâncias e algumas ramificações, fortemente amiloides, e basidiósporos grandes, oblongo-elipsóides.

Assim como observado por Gomes-Silva et al. (2011), os espécimes do PEFI apresentaram basidiósporos levemente menores que os descritos por Ryvarden (2004), que relata para esta espécie basidiósporos maiores, 12-15 × 6-7,5 $\mu \mathrm{m}$. Primeira citação para o Estado de São Paulo. 

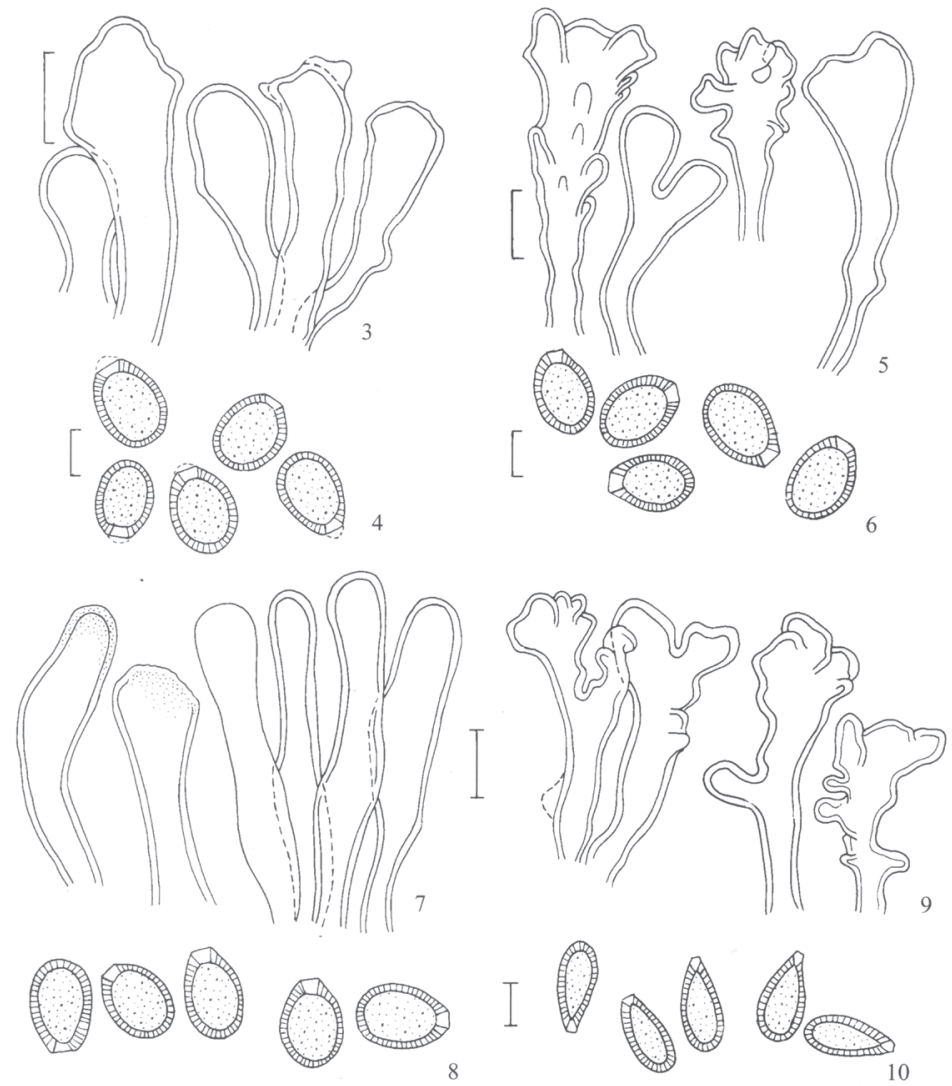

Figuras 3-4. Ganoderma multiplicatum. 3. Células da cutícula. 4. Basidiósporos. Figuras 5-6. Ganoderma orbiforme. 5. Células da cutícula. 6. Basidiósporos. Figuras 7-8. Ganoderma perzonatum. 7. Células da cutícula. 8. Basidiósporos. Figuras 9-10. Ganoderma zonatum. 9. Células da cutícula. 10. Basidiósporos. Barras de escala $=10 \mu \mathrm{m}(3,5,7,9) ; 5 \mu \mathrm{m}(4,6,8,10)$.

Figures 3-4. Ganoderma multiplicatum. 3. Cuticle cells. 4. Basidiospores. Figures 5-6. Ganoderma orbiforme. 5. Cuticle cells. 6. Basidiospores. Figures 7-8. Ganoderma perzonatum. 7. Cuticle cells. 8. Basidiospores. Figures 9-10. Ganoderma zonatum. 9. Cuticle cells. 10. Basidiospores. Bars $=10 \mu \mathrm{m}(3,5,7,9) ; 5 \mu \mathrm{m}(4,6,8,10)$.

\section{Agradecimentos}

Os autores agradecem ao CNPq, pelas bolsas de iniciação científica dentro do programa PIBIC concedidas ao segundo e terceiro autores; à FAPESP pelo apoio financeiro (processo 04/04310-2).

\section{Literatura citada}

Bicudo, D.C., Forti, M.C., Bicudo, C.E.M. 2002. Parque Estadual das Fontes do Ipiranga (PEFI): unidade de conservação que resiste à urbanização de São Paulo. Secretaria do Meio Ambiente do Estado de São Paulo, São Paulo.

Bononi, V.L.R., Trufem, S.F.B. \& Grandi, R.A.P. 1981. Fungos macroscópicos do Parque Estadual das Fontes do Ipiranga, depositados no Herbário do Instituto de Botânica. Rickia 9: 37-53.

CABI. 2011. Index fungorum. http://www.indexfungorum. org (acesso em 19.07.2011).
CBS-KNAW. 2011. Aphyllophorales database. http://www. cbs.knaw.nl/databases/aphyllo/database.aspx (acesso em 19.07.2011).

Campacci, T.V.S. \& Gugliotta, A.M. 2009. A review of Amauroderma in Brazil, with A. oblongisporum newly recorded from the neotropics. Mycotaxon 110: 423-436.

Fidalgo, O. 1968. As microestruturas e sua importância na sistemática dos fungos superiores. Rickia 3: 117-159.

Fidalgo, O. \& Bononi, V.L.R. (coords.). 1984. Técnicas de coleta, preservação e herborização de material botânico. Instituto de Botânica, São Paulo.

Furtado, J.S. 1981. Taxonomy of Amauroderma (Basidiomycetes, Polyporaceae). Memoirs of the New York Botanical Garden 34: 1-109.

Gibertoni, T.B.\& Cavalcanti, M.A.Q. 2003. A mycological survey of the Aphyllophorales (Basidiomycotina) of the Atlantic Rain Forest in the State of Pernambuco, Brazil. Mycotaxon 87: 203-211. 
Gilbertson, R.L. \& Ryvarden, L. 1986. North American Polypores. Fungiflora, Oslo.

Góes-Neto, A. \& Baseia, I. 2006. Filo Basidiomycota. In: L.P. Gusmão \& L.C. Maia (eds.). Diversidade e Caracterização dos Fungos do Semi-Árido Brasileiro. Associação Plantas do Nordeste, Recife, pp. 141-159.

Gomes-Silva, A.C. \& Gibertoni, T.B. 2009. Checklist of the aphyllophoraceous fungi (Agaricomycetes) of the Brazilian Amazônia. Mycotaxon 108: 319-322.

Gomes-Silva, A.C., Ryvarden, L. \& Gibertoni, T.B. 2011. New records of Ganodermataceae (Basidiomycota) from Brazil. Nova Hedwigia 92: 83-94.

Gugliotta, A.M., Fonsêca, M.P. \& Bononi, V.L.R. 2010a. Additions to the knowledge of aphyllophoroid fungi (Basidiomycota) of Atlantic Rain Forest in São Paulo State, Brazil. Mycotaxon 112: 335-338.

Gugliotta, A.M., Silveira, R.M.B, Loguercio-Leite, C., Campos-Santana, M., Gibertoni, T.B., Drechsler-Santos, E.R., Gomes-Silva, A.C. \& Baltazar, J.M. 2010b. Polyporales In: Forzza, R.C. et al. (orgs.) Catálogo de plantas e fungos no Brasil. Jardim Botânico do Rio de Janeiro, Rio de Janeiro, v.1, pp. 196-210.

Jesus, M.A. 1993. Basidiomicetos lignocelulolíticos de floresta nativa e de Pinus elliottii Engelm. do Parque Estadual das Fontes do Ipiranga, São Paulo, SP. Hoehnea 20: 119-126.

Kirk, P.M., Cannon, P.F., Minter, D.W. \& Stalpers, J.A. 2008. Dictionary of the Fungi. 10 ed. CAB International, Wallingford.

Leonard, A.C. 1998. Two Ganoderma species compared. Mycologist 12: 65-68.

Loguercio-Leite, C., Groposo, C. \& Halmenschlager M.A. 2005. Species of Ganoderma Karsten in a subtropical area (Santa Catarina State, Southern Brazil). Iheringia, Bot. 60: 135-139.

Meijer, A.A.R. 2006. Preliminary list of macromycetes from the Brazilian State of Paraná. Boletim do Museu Botânico Municipal 68: 1-55.
Moncalvo, J.-M. \& Buchanan, P.K. 2008. Molecular evidence for long distance dispersal across the Southern Hemisphere in the Ganoderma applanatum-australe species complex (Basidiomycota). Mycological Research 112: 425-436.

Reck, M.A, \& Silveira, R.M.B. 2008. Polyporales (Basidiomycota) no Parque Estadual de Itapuã, Viamão, Rio Grande do Sul. Revista Brasileira de Biociências 6: 301-314.

Ryvarden L. 1991. Genera of Polypores: nomenclature and taxonomy. Fungiflora, Oslo.

Ryvarden L. 2004. Neotropical Polypores: Part 1. Introduction, Ganodermataceae \& Hymenochataceae. Fungiflora, Oslo.

Silveira, R.M.B., Reck, M.A., Graf, L.V. \& Sá, F.N. 2008. Polypores from a Brazilian pine Forest in Southern Brazil: pileate species. Hoehnea 35: 619-631.

Teixeira, A.R. 1962. As microestruturas do basidiocarpo e sistemática do gênero Fomes (Fries) Kickx. Rickia 1: 13-93.

Teixeira, A.R. 1995. Método para estudo das hifas do basidiocarpo de fungos poliporáceos. Instituto de Botânica, São Paulo.

Torrend, C. 1920. Les polyporacées Du Bresil. Broteria, série Botânica 18: 121-142.

Torres-Torres, M.G., Guzmán-Dávalos, L. \& Gugliotta, A.M. 2008. Ganoderma vivianimercedianum sp. nov. and the related species, G. perzonatum. Mycotaxon 105: 447-454.

Westphalen, M.C., Reck, M.A. \& Silveira, R.M.B. 2010. Polypores from Morro Santana, Rio Grande do Sul, Brazil (Fungos Poróides do Morro Santana, Rio Grande do Sul, Brasil). Hoehnea 37: 647-662.

Zhao, J.D. 1989. The Ganodermataceae in China. Bibliotheca Mycologica 132: 1-176. 